\title{
Project Approach to Learning in Early Childhood Education
}

\author{
Kalpana Vengopal ${ }^{1^{*}}$ \\ ${ }^{1}$ Department of Education, Regional Institute of Education, Manasagangotri, Karnataka, India \\ *Kalpana Venugopal, E-mail: kalpanavp@rediffmail.com
}

\begin{abstract}
This paper deals with Project approach to learning in early childhood education. It draws on the fluid and continuous relationship in learning and teaching with renewed insights. It highlights the context for an emergent curriculum through child-initiated activities that are extended by teachers appropriately and innovatively. The intent of the paper is to portray children's learning through an approach that involves them.

This is a qualitative research paper. It provides for the context where in project approach was used in an ECE center in India; a narrative of the field notes of an exemplar project topic; interspersed with discussion on the insights drawn from developmentally appropriate activities; and concludes with its bearing on advances in teaching.
\end{abstract}

\section{Keywords}

project approach, circle-time, emergent curriculum, developmentally appropriate practice

\section{Introduction}

The early childhood stage (6-8 years of a child's life) is globally acknowledged to be the most critical period for lifelong development. If this stage is not embedded in or supported by a stimulating and enriching physical and psychosocial environment, the chances of the child's brain developing to its full potential are considerably and often irreversibly reduced. What follows logically is the crucial importance of investing in these early years to ensure an enabling environment for every child, and thereby a sound foundation for further learning. Unfortunately, in India, most schools for this age group follow undesirable practices. The programs are merely a downward extension of primary education (Kaul, 1999). The heavy curriculum exposes children to rote learning and is rigidly structured at an age when they are not developmentally ready for it. Children spend most of the time writing, working with books, or engaged in number work thus resulting in a formal method of learning. There is little or no scope for "learning by doing"/experiential learning. The danger of early formal instruction is seen as a potential threat to the child's motivation for learning (National Curriculum Framework, NCERT, 2005). Children have their own set of learning priorities, and this is self-directed. When adults intrude into this area of self-directed learning and insist on imposing their own learning priorities like reading and writing, they interfere with this self-directed impulse and undermine the child's sense of initiative (NUEPA, 2009). 
The Position Paper of the National Focus Group on Early Childhood Education (NCERT, 2005) delineates exploration, experimentation, engagement, challenge, opportunity, guidance, support, cooperation, sharing etcetera as the kinds of experiences to be nurtured in children at this stage. Children also need to learn through innovation and problem solving. This requires a new kind of education-one that inspires, connects, and empowers students. The Project Approach does just that by connecting students to their local and global communities thus providing them with real-world experiences beyond the classroom. It helps building on the individual needs, interests, and strengths of all students-allowing children to work, where appropriate, at their own pace. It also hones their literacy and communication skills by enabling students to use a variety of media to share the process and product of their project work. It also helps in integrating content knowledge and skills from a variety of disciplines, so that students come to see and make cross-curricular connections (Helm \& Katz, 1994). Lee (2002) reiterates that Project Approach to learning engages students' natural bent for discovery through observation, play, hands-on tasks and real-world challenges. Project-based learning complements systematic instruction in basic skills by making discrete bits of information relevant. Children have a strong disposition to explore and discover. The Project Approach is built on the natural curiosity of children, that enable them to interact, connect, communicate, inquire, problem solve, reflect and more. Such authentic learning extends beyond the walls of a classroom. It essentially relates learning to real life. It recognizes the potential in every child. Opportunities can be provided for children to contribute in original and creative ways (Jane, 1998).

Project Approach is a method of teaching, in which a child or a group of children conducts an in-depth study of a particular topic. The Project Approach is incorporated into the curriculum but does not always constitute the entire curriculum.

\section{The Place of Project Approach in the Curriculum}

Advocates of the project approach do not suggest that project work should constitute the entire curriculum (Helm \& Katz, 1994; Jane, 1998; Clark, 2006). They suggest that it be best seen as complementary to the informal parts of the curriculum for very young children. Project work is not a separate subject, like science; it provides a context for applying scientific concepts and skills. Nor is project work an "add on" to the fundamentals; it should be treated as integral to everything included in the curriculum (Katz, 1993). Both systematic instruction and project work have an important place in the curriculum (Vaconcelos, 2007).

A student's nature to work in a classroom is reinforced by a sense of purpose. In systematic instruction, the purpose of the work is normally, the responsibility of the teacher. The teacher determines what is required based on his/her understanding of what students do not know, cannot do, and the best way of helping them acquire the necessary skills and understandings. The teacher's judgment of students' needs prevails in directing their work. In project work, however, the teacher views the students from a totally different perspective, by seeing them in terms of what they know to do, their acquired set of skills, and 
how they might use them for their own purposes (Chard, 2014).

Students can shoulder some responsibility for the various tasks they undertake in project activities. For example, the teacher can facilitate them to choose the level of challenge with which they feel confident, the duration of time they plan to work, the level of detail or elaboration, which might be appropriate for them, and their choice to work alone or with a peer. Engaging in such choices provides scope for students to take onus of the work and accept responsibility for the effort and the quality of ideas that they bring to the activity (Chard, 2014).

Different criteria can be considered for selecting project topics. Firstly, the topic should be closely related to children's daily experience. At least a few of them should be familiar with the topic to be able to raise questions about it. Secondly, apart from basic pre-literacy and pre numeracy skills, the topic should provide for the integration of subjects such as science, social studies, and language arts. Thirdly, the topic should be rich enough so that it can be explored for at least a week. Fourthly, the topic should be such that it is more suitable for examination in school than at home (Katz, 1993).

The daily schedule is flexible and loosely structured. It encourages student initiative by providing them with materials, equipment and time to pursue their chosen activities. It provides teachers with a framework for guiding children's activities through topic webs designed by teachers toward sequenced learning goals. Topics at the ECE level could include, senses, my family, my friends, water, food, clothes, animals, birds and insects, homes, flowers, balls, communication and transportation, and many more that are relevant to the child's learning at this age. The duration of a topic may range from seven to ten days, depending on the interest of the learners and the emergent curriculum.

Once the topic has been selected, teachers usually start by designing a web, or concept map, by brainstorming with the children. Displaying a topic web and subtopics can be used for continuous de-briefing discussion sessions as the project work proceeds. During preliminary discussions, the teacher and children engage in answering questions of that which they seek to investigate.

\section{Project Web}

A Project Web is a pictorial representation of a topic and related subtopics. A web is designed by a teacher to anticipate what can be learned about topic. It is designed based on children's interests; focuses on topics that are relevant to them and links previous knowledge to new knowledge. Webs are emergent as they are designed by engaging in discussion with children. Activities are designed accordingly and resources for the same are sought. These resources support children's learning styles in a variety of interactive and collaborative ways. The resources and materials include manipulative, naturally found objects, instruments, toys, field trips, books, videos, magazines, brochures, guest speakers/experts, artifacts, music, puppets, masks, charts, models, all of which support children's learning styles in a variety of interactive and collaborative ways that traditionally engage children.

Although project work in the early childhood stage, is not new in many parts of the world and the interest in involving children in group projects has been growing for several years, it is fairly new in the Indian 
context. The renewed interest is based researches (Kandel \& Hawkins, 1992; Sharan \& Sharan, 1992; Beneke, 1994; Kay \& Katherine, 1996; Capezzuto, Sheila, \& Denise, 2001; Vasconcelos, 2007; Beneke \& Ostrosky, 2007; Kogan \& Pin, 2009) and the impressive reports of group projects conducted by children in the pre-primary schools of Reggio Emilia (Edwards et al., 1993).

The present study is about the Project approach to learning, which was employed in the Early Childhood Education (ECE) program for children of the age group 4.5 to 5.5 years, in an ECE center in India. The objectives were geared towards studying the process of learning and teaching children in the ECE stage through project approach. The investigator employs a narrative interspersed with excerpts of field notes of an exemplar project topic. This inherently provides for a series of developmentally appropriate activities that propel an emergent curriculum and discussion of the process of learning and teaching there in. Since the emphasis is on the process of learning, planning and designing activities is not included in here.

\section{A Narrative of the Project}

The day began by a brainstorming session on trees, which enabled the teacher to map the course of the topic and the activities. Talking to children about the plan of work provided an opportunity for teachers to encourage and respond to each child's ideas. This facilitated in strengthening work plans. It enabled to understand and gauge each child's level of development, thinking style \& interest. Children and teachers benefitted from these discussions. Children felt reinforced and ready to begin work. Teachers ideated on the opportunities for extension, difficulties children might face, and problem solving that may be required.

The brainstorming session set the exploration visit in the campus where in the school is located. The sprawling campus is home to a large number of a wide variety of trees. They trotted along to the central area of the campus. Children were free to see and gather all they could about trees. They collected different objects from around the trees and filled their paper bags. Those children who had filled their bags helped others gather. Some gathered anything they saw, some were choosy to pick only that which they had not gathered, some chose to move to different trees, while there was one who picked only one kind of object and was very slow. This child welcomed help only from one other child who made her understand that she could gather a variety of other objects too. The teachers chose not to interfere in the process of exploring.

On returning and refreshing, it was circle-time. Each child exhibited the objects which included twigs, leaves, flowers, pieces of bark, feathers, fruits, seeds, dried droppings, plastics, strings, stones, sand, gum/resin, fiber, etc. Each one spoke about their collection and tried to name the tree. Some of them named the tree by the color/shape of its flowers, others by the location of it in the campus, while others by the size and shape. The teachers discerned that though the learning context was the same, children represented knowledge in their own way. Children prompted each other in naming the tree. Those who had helped others in the gathering task were eager to say so. In the course of presenting the objects 
children were quick to disapprove of some objects as those representing a tree, such as stones, sand, plastic and strings. Two children argued that stones and sand were a part of the tree because the tree stands on them! Some children ran in to get picture books, encyclopedia and picture cards on fruits, flowers and trees. They browsed for pictures of trees and urged the teacher to read aloud the names. The teacher facilitated the course of participation, provided probes and assisted when children sought for aid. The teacher deliberately brought to the front the acts of help rendered by some without naming the children.

Recall strategies during circle-time included demonstration of various developmentally appropriate activities and verbally recalling the events of work time. The teacher supported children's linking of the actual work to their reporting. These reviews provided children to reflect on what they did and how it was done. It brought about closure to children's work-time activities. Expressing their ideas and experiences in words and sentences also facilitated children's language development. As reiterated by Pascal (2009), it also enables children to represent and share their mental schemes.

The video on trees was followed by a brief discussion on what they visualized and their exploration. Many of them tried to rename the trees they saw and the objects they gathered. Some of them spoke of trees they imagined they saw. Children drew figures of big trees on the ground and designed it with their find. Most of them were able to fill the trunk space of the tree with twigs, the upper part with flowers, fruits, seeds and leaves. The two who had gathered stones and sand, filled the lower end of the figure with it. Some chose to leave behind the plastics and strings while others spread them below the tree. One of them who had picked resin/gum placed it in the trunk space though she found it on the ground. Some who gathered objects from different trees were keen to separate them on different tree drawings. Some who finished their task helped others arrange theirs. One of them went about correcting his peers' tree drawings (some objected to this, while others allowed him to do so and still others called out to him for help). Some couldn't finish the task and sought for help either from friends or teachers. One of them chose not to engage in this task and spread the material gathered on the floor in circles. The teacher let her have it her way and ensured that she enjoyed whatever she was doing. Instead of focusing on children's deficits, emphasis is laid on the development of broad physical, social and cognitive abilities essential for all children. This allows for children to progress at their pace, and provides for their individual and special needs. The project approach allows for engaging with resources at varying degrees of difficulty, so that all children can participate (Beneke \& Ostrosky, 2007).

Next day, children were quick to pick up the lyrics and tune of a song "Swinging on the mango tree" for which they suggested actions and dance steps. Their vocabulary was enriched through the lyrics of the song. As they watched the video of their rendition, they laughed at each other's steps. They suggested we go out to swing on the mango tree. On probing, some of them were able to locate mango trees in the campus, which they had seen on their way to school. Two of them offered that we go to the mango trees in their garden in the campus. We brainstormed on ways of making swings on the mango 
trees. They were able to list resources and described ways of building swings. They also tried to guess the materials that could be used to make the swing strong enough to bear their weight.

As this was not a part of the plan, the teachers had to arrange for a visit to the mango grove in the campus and tie up ropes and cushion as swings on trees. As teachers, we create the environment and experiences based on what children are curious about and are interested in. In an emergent curriculum, the course of the learning engagement determines its progress. Children's lives offer a rich set of topics for projects; which would include learning about themselves, their families, and the larger community in which they live (Essa \& Rogers, 1992). They were paired for the swing activity so that one would swing, while the other would rock. Some children refused to give a chance to the other and when this happened some of them broke away from the pair and joined another pair; some threatened not to rock the other; still others kept quiet; some sought the intervention of teachers and some had decided on a mechanism about their turns on the swing.

Since it was not the season for mangoes the group had to return without any. While we walked back, one of them suggested we return to the grove in the holidays (summer time), when there would be plenty of fruit. This prompted the teachers to initiate the discussion on seasons, fruits and flowers. On their return the teachers found it apt to let them watch the video on the same followed by a discussion. This discussion allowed them to come up with new vocabulary followed by a word game on matching alphabet/phonic sounds with names of fruits and flowers.

The discussion concluded with an all season fruit - the coconut. This was the thread for the next day's activity on drawing \& coloring a coconut tree. Coconut trees were drawn differently- big or small, single or many, scattered or in rows, amidst water and another with a boat. They spoke elaborately about their drawings describing that which was visible and that which was not too. One child interpreted his drawing saying that all the coconuts were on the ground because a man had plucked them and he had gone to fetch a basket. Another said the hanging figure on the trunk of the tree was a man; another said there was a monkey plucking coconuts but was not clearly visible as it was trying to hold on to the trunk tightly. One of them described the coconut tree near the beach while another said it was on the lake as they had seen them on their journey to their hometowns. The one with the boat had a long tale to tell about a thief who was filling the boat with coconuts to take them home.

This was followed by an exploratory visit to the coconut grove where they could actually watch men climb up trees and pluck coconuts. They queried about the rough surface of the trunk, big fan-shaped leaves, fruits that fell off on their own, colors, shapes and sizes of coconuts, trees that were slanting, water in the pit at the foot of the tree, insects that had crawled into the coconut fiber and men collecting and piling coconuts in trucks. They tried to lift coconuts and found some to be light while some were heavy. They tried to associate weight of the coconuts with their color. The gardener intervened and explained that those that were brown had little or no water and so were light while the green ones were heavy with water. They would not wait for responses as each was excited to ask and prompt an answer. The teacher directed the course of questions and responses, allowing for them to guess the responses. 
Some of them were engaged in counting the number of coconuts that were getting piled around each tree. We were all surprised with the tender coconut drink offered in the grove. We then sat in the shade to play a game of passing the parcel with a coconut. During circle time some of them spoke of carts carrying coconuts, coconut curry and chutney, coconut shells used as fuel, the flower used during a particular festival at home. One described of her granny making brooms from dried coconut leaves and ropes from coconut coir. This fascinated them all. The teachers helped children integrate concepts and process skills through firsthand explorations and extended discussions. The whole course of an activity had three phases: beginning the study, investigations, and celebrating learning.

The next day was a surprise for all of them as there was granny to actually demonstrate the making of brooms and coir rope! They were keen to try their hands at it. They worked in small groups where everyone had a task to do. Each group made a broom and a piece of rope. When children are allowed to pursue their interests they engage deeply in learning. A project topic provides the context for real-life activities, explorations, and inquiries (Lee, 2002). After break-time they wanted to share their experiences. The teacher facilitated the discussion and at the end she directed the discussion towards group work, tasks of each member, the completed activity and the finished product. Kostelink, Soderman and Whiren (2004) pointed that developmentally appropriate activities engage and allow students to explore concepts from a variety of perspectives and viewpoints. Furthermore, they highlighted that a thematic curriculum at the preschool stage provides children with opportunities for independent learning, problem solving, divergent thinking, risk-taking and choice.

After the story session on "The monkeys on the coconut tree" with puppets and masks, some children queried about the absence of monkeys on trees in the campus. They asked where all the monkeys had gone; whether monkeys lived on other trees; and why monkeys live on trees. Children came up with different reasons and arguments. It ended on the note that monkeys had fled from trees because they were stoned as men didn't want to share fruits with them. Circle time allowed for children to construct meaning by sharing their experiences. This places a strong emphasis on children's social construction of knowledge through their relationships within the context of collaboration, dialogue, conflict, negotiation, and cooperation with peers and adults (Curtis \& Carter, 2007).

The next day we went out exploring trees in the campus to know more about sizes of trees. Children tried to respond on how they could know about the height (tallness) of trees. Some said they couldn't measure its height without a big ladder. The teacher probed about its width (fatness). Some tried to encircle the trunk with their arms and called out to their friends to join them. They tried to say the trunk was very fat as many of them had to hold hands. The teacher then paired them and demonstrated the activity of measuring the trunk (circumference) with a ball of string (cutting off as much string as required), and the children followed suit. Later as each pair stood holding the ends of the string, they found that some of their friends were further apart. They could not reason for this. So, the teacher explained to them that some strings were longer. The teacher further laid each string on the ground in a circle. This enabled children to know that some trees were fat while some were thin; and larger the 
circle, fatter the tree. This draws a parallel with Katz (1993), who pointed that to make sense of experiences, to theorize about cause and effect, to hypothesize explanations, to account for observations, and to analyze and synthesize available information are a variety of intellectual dispositions, which can be seen when children are engaged in investigations around them.

Children also tried to gauge the size of trees by its distance from them; they felt trees farther away were small. So, the teacher walked them near the tree and then they said it became big. Piaget examined the impact of children's active, physical interactions with the environment on the construction of knowledge. According to Piaget (1973), “A student who achieves a certain knowledge through free investigation and spontaneous effort will later be able to retain it" (p. 93). Piaget's (1973) reference to children's "investigation" (p. 93) suggests the role of the child as that of a researcher. The same has been reiterated by John Dewey (1991). They were able to learn words like far, near, small, big, tall, short, in, out, up, down, there and here.

We were looking out for a place to break for snack and children chose the big banyan tree. As we sat under the tree they observed that this tree looked odd, as there were many trees joined together and the roots ran up and down. We finished our snack and had a little chat about our expedition. On probing about the choice of the place for the break they came up with several responses. Some said that they wanted a shady space; some said a big space and others related this to the big neem tree in the school where they had their lunch. The teacher found an opportune moment to discuss about the importance of shady trees. Children shared their experiences about enjoying their holidays while playing under the tamarind tree. They ventilated their displeasure about the tree being cut down. Children construct meaning from their own experiences and thus connect and contextualize knowledge (DeVries, Zan, Hildebrandt, Edmiaston, \& Sales, 2002). They related the sounds of different birds and insects on the tree with those they had previously heard in school during "silent time" in the mornings and mimicked them. They summarized about all that trees offered- fruits, flowers, seeds, wood, etc. The teacher related the story of "The Banyan Tree" and let them complete it as they fancied.

Before returning, children were keen to collect something from around the trees. As this wasn't planned, they had to collect them in their snack bags. This time the teacher allowed them to opt a group. The groups were of flowers, leaves and twigs. Each one in the group collected only that object which the group represented. On their return they worked in groups to display the objects they had collected. The displays included floral rangoli (design), leaves rangoli, garland of flowers and leaves, scrapbook of different shaped leaves, the alphabets "TREE" with twigs, and a twig house.

\section{Discussion}

According to Williams and Fromberg (2011), "Projects can promote and reflect the cohesiveness of the curriculum, curricular integration across subject matter and/or developmental domains... Teachers have found varied project topics to plan the curriculum, to focus ways to generate new ideas, and to 
select activities from alternative sources. Project topics are also useful to communicate to others what is happening in an early childhood educational setting" (p. 318).

Teachers ensured that there were no tasks that involved memorizing lists or symbols, responding to questions that had correct answers, nor practiced routine tasks that could be assessed as right or wrong. Kogan and Pin (2009) point out that project approach encourages teachers to start with students' strength and utilize their relevant background knowledge. Teachers continually and positively encouraged and supported children's interests and involvement in activities. Beneke and Ostrosky (2007) too found that kindergarten teachers had a positive perception towards implementation of project approach in the teaching and learning process. Teachers planned for key experiences that might broaden and strengthen children's emerging abilities. Teacher innovativeness is central to designing learning that is learner focused (Branscombe, 2003). Children generated many of these experiences on their own while some required teacher guidance. Many key experiences were natural extensions of children's ideas and interests. A rich range of developmentally appropriate experiences ensures the engagement of all kinds of learners (Gestwicki, 2007).

The developmentally appropriate way to support children's learning is through child-initiated exploration, which an adult scaffolds (Bredekamp \& Copple, 1997). The traditional importance given to spontaneous play, song \& movement, collecting artifacts/objects and creative art for young children as a natural way to learn cannot be sabotaged and bargained for literacy and numeracy programs that provide readiness for the next grade or class. Early childhood curriculum is not just intended to help children master the basic skills of literacy and numeracy, where in the child is made to feel dependent on adult instruction to cram such academic knowledge and skills (Katz \& Chard, 1989). It is an active and interactive curriculum that can actually see young children as active constructors of knowledge, which is a major goal of the thematic curriculum.

\section{Conclusion}

We begin with the idea that through constructing meaning together (both teacher and child) we are able to deepen one another's learning and understanding; thereby, incessantly building relationships (Stuipansky, 1997). This facilitates exchange of ideas and thoughts that truly engage one another in the process of learning through an approach such as the project approach. This is an integral aspect of an emergent curriculum that emerges with the engagement of both sides.

As teachers we could create a prospect for deep reflection on practice if we inquire into our image of the child. This would certainly have a bearing on our ways of engaging with them by employing suitable approaches such as this. We would see that our view of the child impacts our pedagogy. The extent to which we are disposed to listen, observe and provide opportunities for children to be self-directed in their learning would become the benchmark of an indication of the shift in perspective. The extent to which we renounce some of our "control" and "step aside", would actually allow for listening, observing and reflecting on the learning processes that children engage in. This would also 
become the opportune moments for children to reign in, learn and construct meaning with peers rather than accept versions of pre-constructed meanings from teachers. The project approach provides the fertile ground for such a relationship in learning and teaching.

\section{References}

Beneke \& Ostrosky. (2007). Teachers'Views of the Efficacy of Incorporating the Project Approach into Classroom Practice with Diverse Learners. Retrieved from http://www.ceep.crc.uiuc.edu/eecearchive/digests/ed-cite/ed448856.html

Beneke. (1994). Implementing the Project Approach in Part-time Early Childhood Education Programs. Early Childhood Research and Practice, 2(1). Retrieved from http://www.ecrp.uiuc.edu/v2n1/index.html

Branscombe, A. N. (2003). Early Childhood Curriculum: A Constructive Perspective. Boston, Massachusetts: Houghton Mifflin Company.

Bredekamp, S., \& Copple, C. (Eds.). (1997). Developmentally Appropriate Practice in Early Childhood Programs. Washington DC: National Association for the Education of Young Children.

Capezzuto, S. M., \& Denise. (2001). Using experts to enhance classroom projects. Young Children, $56(2), 84-85$.

Chard, S. (2014). The Project Approach. Retrieved from http://www.projectapproach.org

Clark, M. (2006). Changing Classroom Practice to Include the Project Approach. Early Childhood Research and Practice, 8(2). Retrieved from http://www.ecrp.uiuc.edu/v8n2/index.html

Curtis, D., \& Carter, M. (2007). Learning Together with Young Children. St. Paul, MN: Red leaf Press.

DeVries, R., Zan, B. C., Hildebrandt, R. E., \& Sales, C. (2002). Developing constructivist early childhood curriculum: Practical principles and activities. New York: Teachers College Press.

Dewey, J. (1991). How we think. Buffalo, NY: Prometheus Books.

Edwards, C., Gandini, L., \& Forman, G. (Eds.). (1993). The hundred languages of children: The reggioemilia approach to early childhood education. Norwood: New Jersey.

Essa, E., \& Rogers, P. R. (1992). An early childhood curriculum: From developmental model to application. Albany, NY: Thomson Delmar.

Gestwicki, C. (2007). Developmentally Appropriate Practice: Curriculum and Development in Early Education (3rd ed.). Clifton Park, NY: Delmar Cengage Learning.

Helm, H., \& Katz, L. G. (1994). Young Investigators: The Project Approach in the Early Years. Retrieved from http://www.ceep.crc.uiuc.edu/eecearchive/digests/1994/lk-pro94.html

Jane, M. (1998). The Project Approach: A different way to plan curriculum. Young Children, 53(4), 55-59.

Kandel, E. R., \& Hawkins, R. D. (1992). The Biological Basis of Learning and Individuality. Scientific American, 267(3), 78-86. 
Katz, L. G. (1993). Dispositions: Definitions and implications for early childhood practice. Champaign,

IL: ERIC Clearinghouse on Elementary and Early Childhood Education (ED360104).

Katz, L. G., \& Chard, S. C. (1989). Engaging children's minds: The project approach. Norwood, NJ: Ablex.

Kaul, V. (1999). Early childhood care and education in the context of EFA (Paper prepared for the Governmentof India: Education for All-The Year 2000 Assessment Report). New Delhi: NUEPA.

Kay, A., \& Katherine, W. (1996). Learning about moths. Texas Child Care, 20(2), 32-37.

Kogan, Y., \& Pin, J. (2009). Beginning the Journey: The Project Approach with Toddlers. Early Childhood Research and Practice, 11(1). Retrieved from http://www.ecrp.uiuc.edu/v11n1/index.html

Kostelink, M. J., Soderman, A. K., \& Whiren, A. P. (2004). Developmentally appropriate curriculum: Best practices in early childhood education. Upper Saddle River, NJ: Merrill.

Lee, S. (2002). Explore, Question, Ponder, and Imagine: Projects give kids the chance to delve deeply and find their own way through challenging intellectual terrain. Northwest Education, 7(3), 2-7.

National University of Educational Planning and Administration (NUEPA). (2009). Early Childhood Care and Education in India, EFA-Mid Decade Assessment. New Delhi, India: NUEPA.

NCERT. (2005). National Curriculum Framework. New Delhi: NCERT.

NCERT. (2005). National Focus Group on Early Childhood Education. New Delhi: NCERT.

Pascal, C. (2009). With Our Best Future in Mind: Implementing Early Learning in Ontario. Toronto, ON: Queen's Printer for Ontario.

Piaget, J. (1973). To understand is to invent: The future of education. NY: Grossman Publishers.

Sharan, S., \& Sharan, Y. (1992). Expanding cooperative learning through group investigation. New York: Teacher's College Press, Columbia University.

Stuipansky, S. W. (1997). Building Understanding Together: A Constructivist Approach to Early Childhood Education. Boston, Massachusetts: Cengage Learning.

Vasconcelos, T. (2007). Using the Project Approach in a Teacher Education Practicum. Early Childhood Research and Practice, 9(2). Retrieved from http://www.ecrp.uiuc.edu/v9n2/index.html Williams, L. R., \& Fromberg, D. P. (Eds.). (2011). Encyclopedia of Early Childhood Education. London, U.K.: Routledge. 